\title{
Highly Photoactive Polythiophenes Obtained by Electrochemical Synthesis from Bipyridine-Containing Terthiophenes
}

\author{
Fabrizio Sordello* ${ }^{\mathbb{D}}$, Claudio Minero $®$, Guido Viscardi and Pierluigi Quagliotto * \\ Dipartimento di Chimica, Università degli Studi di Torino, via Pietro Giuria 7, 10125 Torino, Italy; \\ claudio.minero@unito.it (C.M.); guido.viscardi@unito.it (G.V.) \\ * Correspondence: fabrizio.sordello@unito.it (F.S.); pierluigi.quagliotto@unito.it (P.Q.)
}

Received: 10 December 2018; Accepted: 18 January 2019; Published: 22 January 2019

\begin{abstract}
According to numerous previous reports, a Z-scheme with two photon absorbers is the most promising strategy to achieve artificial photosynthesis, but in addition to two efficient catalysts-one for oxygen evolution, the other for $\mathrm{CO}_{2}$ reduction-two different and complementary semiconducting sensitizers are required. Here we present the synthesis of two bipyridine-functionalized terthiophenes, which can be electropolymerized to give photoactive p-type semiconductors the capability to perform as photocathode in photoelectrochemical cells for water photosplitting or artificial photosynthesis. Indeed the bipyridine moiety in their structure allows the binding of transition metal carbonyl complexes employed in $\mathrm{CO}_{2}$ reduction, and their band-gap is suitable for the coupling with wide band-gap semiconductors, which have already found application as photoanodes. Finally, they are characterized by photogenerated charge carrier density between 1.1 and $1.4 \times 10^{19} \mathrm{~cm}^{-3}$, with first-order recombination constant of $0.7-1.8 \times 10^{-2} \mathrm{~s}^{-1}$. These figures are of the same order of magnitude of their inorganic counterparts and would therefore guarantee photoconductivity of the device and the activation of the organometallic catalysts with which they should be coupled to function as photocathodes for $\mathrm{CO}_{2}$ reduction.
\end{abstract}

Keywords: polythiophene; electrochemistry; semiconductor; p-type

\section{Introduction}

Energy availability at a low cost is a fundamental requisite to maintain the complex society to which we are accustomed. However, environmental sustainability must also be taken into account [1]. Thus, increasing efforts in recent decades have been dedicated to increase energy efficiency, to reduce the energy demand maintaining at least constant the quality of life and to improve the competitiveness of renewable sources such as solar, geothermal and wind power, with significant increase in cumulative capacity and market shares as results [2-5].

In this perspective, artificial photosynthesis represents an important resource, because, converting solar power into chemicals can be complementary to battery technologies and photovoltaics in order to mitigate its intermittent nature and to allow its storage and transportation without needing a power grid. The most promising strategy is to mimic nature to a certain extent, utilizing a Z-scheme (as shown in Figure 1 [6-10]) involving the presence of two absorbers-photoanode and photocathode-and possibly decoupling the tasks of photon absorption and electron transfer, with the surface functionalization of the absorber with a suitable catalyst. Compared to natural photosynthesis, the electronic transport chains are usually simplified and involve a smaller number of intermediate steps. Though simpler, this design is prone to recombination, which usually represents the main path for energy losses [11,12]. 
While the photoanode could reasonably be an inorganic n-type semiconductor decorated with an oxygen-evolving catalyst, for which numerous recent reports are available, [13-16] the photocathode should be a p-type semiconductor with a rather reducing potential of the conduction band (CB). Moreover, to guarantee a non-negligible photovoltage of the device, its energy gap should be at least $1.5 \mathrm{eV}$ to maintain the valence band $(\mathrm{VB})$ potential more positive than the photoanode conduction band (Figure 1). If $\mathrm{CO}_{2}$ has to be reduced and converted to $\mathrm{CO}$ (or to $\mathrm{HCOOH}, \mathrm{CH}_{3} \mathrm{OH}$, or $\mathrm{CH}_{4}$ ), then the coupling to molecular organometallic complexes belonging to the families of $\left[\operatorname{Re}(\mathrm{CO})_{3}(\mathrm{bpy}-\mathrm{R}) \mathrm{Cl}\right][17,18],\left[\mathrm{Mn}(\mathrm{CO})_{3}(\mathrm{bpy}-\mathrm{R}) \mathrm{Br}\right]$ [19], Fe porphyrins [20], and [Cu(bpy-R $\left.)_{2}\right]$ [21] must be envisaged, and a covalent bonding with the photocathode material appears to be one of the most effective strategies. Semiconductive polymers are therefore an appealing solution to produce photocathode materials because of the possibility of functionalization with covalent bonds, ensuring fast electron transfer to the catalytic moiety, and because of the tunability of their energy gap and $\mathrm{CB}$ and VB potentials, thanks to structure modification through molecular engineering [22,23].

Recent works reported large photocurrents, also in aqueous environments [24,25] and encouraging photon efficiency for polyanilines (PANI), polythiophenes and other classes of materials and provided solutions for the main drawbacks of this class of materials, namely low-charge carrier mobility and poor photo- and electrostability [26], which were already reported in the early 1990s by Kalaji et al. [27]. In this context, Hursán and coworkers [28] demonstrated the $\mathrm{CO}_{2}$ photoelectrochemical reduction employing PANI as photocathode, reporting promising photocurrent enhancement under $\mathrm{CO}_{2}$-saturated electrolyte and without the employment of an organometallic catalyst. The mechanism proposed involves the binding of $\mathrm{CO}_{2}$ with the PANI aminic nitrogen forming a carbamate, followed by reduction to alcohols. Although inorganic p-type semiconductors are becoming more available, thanks to the research in photocathodic dye sensitized solar cells, [29] they are less adaptable than their organic counterparts.

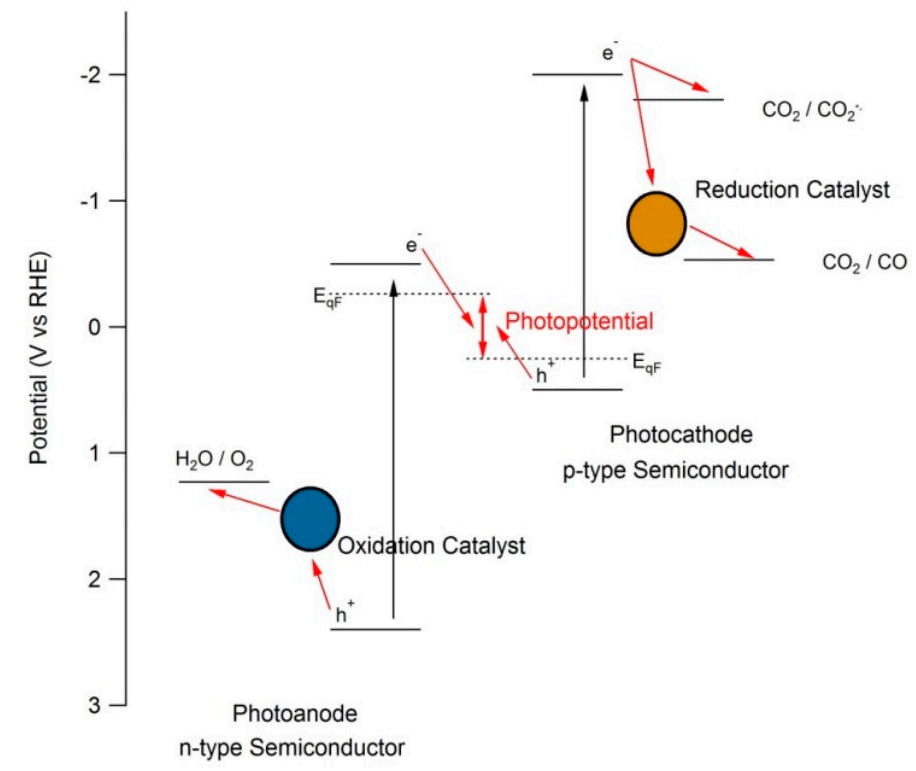

Figure 1. Z-scheme for artificial photosynthesis involving an n-type semiconductor decorated with an oxidation catalyst as the photoanode and a p-type semiconductor functionalized with a reduction catalyst as the photocathode. $\mathrm{E}_{\mathrm{qF}}$ is the quasi-Fermi level under irradiation for electrons and holes in the photoanode and photocathode, respectively, and the photopotential of the device is given by the difference between these two potentials. The standard potentials for the reactions reported are: $\mathrm{CO}_{2}+\mathrm{e}^{-} \rightarrow \mathrm{CO}_{2}^{-} \mathrm{E}^{0}=-1.9 \mathrm{~V}$ vs. RHE (Reversible Hydrogen Electrode); $\mathrm{CO}_{2}+2 \mathrm{H}^{+}+2 \mathrm{e}^{-} \rightarrow \mathrm{CO}+$ $\mathrm{H}_{2} \mathrm{O} \mathrm{E}^{0}=-0.53 \mathrm{~V}$ vs. RHE; $\mathrm{O}_{2}+4 \mathrm{H}^{+}+4 \mathrm{e}^{-} \rightarrow 2 \mathrm{H}_{2} \mathrm{O} \mathrm{E}^{0}=1.23 \mathrm{~V}$ vs. RHE $[17,30]$. 
Among organic polymers, polythiophenes are of particular interest because their properties can be tuned with functionalized with different groups [31] and their band-gap is usually around $2 \mathrm{eV}$, [32] which is optimal in the case of the coupling with wide band-gap semiconductors, such as $\mathrm{TiO}_{2}, \mathrm{WO}_{3}$, $\mathrm{BiVO}_{4}$, and to a lesser extent, hematite [33]. In this way, light absorption is guaranteed for both cell compartments and a sufficient driving force would also be assured to activate the molecular catalyst responsible for $\mathrm{CO}_{2}$ reduction. Furthermore, Re complexes with a terthiophene-containing ligand have demonstrated high activity in $\mathrm{CO}_{2}$ reduction, even when immobilized, with remarkable turn-over number larger than 500 , demonstrating the feasibility of a polythiophene-based photocathode for $\mathrm{CO}_{2}$ reduction [34].

In the present work, we report the synthesis of two bipyridine-functionalized terthiophene monomers and of their homopolymers and copolymers with thiophene, which we characterized at their photoelectrochemical properties with particular attention. Our aim was to perform a functional characterization, simulating as much as possible the working conditions of the real device, probing the photoactivity of the material and its charge carrier dynamics in the dark and under irradiation. The energy gap, photogenerated charge carrier density and recombination constant of the materials here prepared and investigated are very close to inorganic semiconductors such as $\mathrm{TiO}_{2}$, and therefore very promising in the perspective of the application as a photocathode in devices performing artificial photosynthesis.

\section{Materials and Methods}

\subsection{Chemicals}

All chemicals were purchased from Aldrich or Fluka and were used without further purification; all reactions were performed under $\mathrm{Ar}$ atmosphere, in $20 \mathrm{~mL}$ vials that were crimped and sealed with polytetrafluoeoethylene (PTFE) septa caps. The reactions were monitored by GC-MS (Gas-Chromatography-Mass-Spectrometry) and/or thin layer chromatography (TLC) using silica gel as stationary phase on plastic sheets and eluents as reported for the purification in every procedure. The products were purified using a Biotage Isolera automated medium pressure purification system, equipped with UV detector (using variable/fixed wavelength and a Diode array, from 200 to $400 \mathrm{~nm}$ ), working with silica stationary phase. The eluents used for the purifications are indicated, for every product, in the proper synthetic procedure.

NMR (Nuclear Magnetic Resonance) spectra were recorded in $\mathrm{CDCl}_{3}$ with a Bruker Avance 200, working at $200 \mathrm{MHz}$ for ${ }^{1} \mathrm{H}$. Chemical shifts were reported in parts per million $(\delta)$ using tetramethylsilane (TMS) and residual solvent peaks as a reference.

GC-MS were recorded with a Thermo Finningan Trace GC instrument equipped with a Zebron-5MS fused silica column of Phenomenex ( $30 \times 0.25 \mathrm{~mm}$ i.d., $0.25 \mu \mathrm{m}$ film thickness), injector temperature of $250^{\circ} \mathrm{C}$, split flow of $10 \mathrm{~mL} \mathrm{~min}{ }^{-1}$, carrier gas helium at constant flow of $1.2 \mathrm{~mL} \cdot \mathrm{min}^{-1}$. Electrospray ionization-MS experiments were performed with a Thermo Fisher Scientific LCQ Advantage Max ion-trap mass spectrometer, equipped with an Electrospray ionization source.

\subsection{Morphology}

The morphology of the films was studied with AFM (Atomic Force Microscopy) technique by means of a Park System XE-100 microscope.

\subsection{Organic Synthesis}

The synthetic details are reported in the Supplementary Materials (SM). The syntheses were performed by adapting literature methods [35-37]. 


\subsection{UV-Visible Spectroscopy}

To evaluate the electronic band-gaps of the thin films synthesized UV-Vis transmittance spectra were recorded using a Cary $100 \mathrm{UV}$-Vis spectrophotometer, version 9.00 (Varian). Spectra were registered in the $200-900 \mathrm{~nm}$ range $(1.4-6.2 \mathrm{eV})$ at a scan rate of $300 \mathrm{~nm} \mathrm{~min}^{-1}$ with a step size of $0.5 \mathrm{~nm}$; the UV source changeover was set up at $350 \mathrm{~nm}$.

\subsection{Electrochemical Tests}

The electrochemical experiments were carried out with a standard photoelectrochemical set-up composed of a computer-controlled potentiostat, AUTOLAB PGSTAT12, equipped with the FRA2 module for electrochemical impedance spectroscopy (EIS), and a $150 \mathrm{~W}$ LOT Oriel Xe arc lamp as radiation source. Irradiance on the electrode surface was $17 \mathrm{~W} \mathrm{~m}^{-2}$ in the $\mathrm{UV}$ and $255 \mathrm{~W} \mathrm{~m}^{-2}$ in the visible. The electrochemical cell was a conventional three-electrode cell. The counter and reference electrodes were a Pt sheet and an $\mathrm{Ag} / \mathrm{AgCl} / \mathrm{TEACl}(0.1 \mathrm{M}$ in acetonitrile) electrode, respectively. If needed the electrolytic solution was purged with nitrogen gas. Transparent conductive supports (Corning ${ }^{\circledR}$ EXG alkaline earth boro-aluminosilicate glass, $25 \times 25 \times 1.1 \mathrm{~mm}$, Indium Tin Oxide coated on one surface, Rs $=9-15$ ohms, Transmission $>80 \%$ ) were obtained from Delta Technologies Ltd. (Loveland, CO, USA).

\section{Results}

\subsection{Organic Synthesis}

Because the electropolymerization of thiophene or terthiophene monomers is an easy process to produce films of conductive polythiophenes, we prepared terthiophene monomers, side-functionalized with a bipyridine ligand. Two model compounds were chosen. The first is a compound where an alkyne spacer is connecting the $3^{\prime}$-position of the terthiophene with the 4-position of the bipyridine, TABP (TerthiopheneAlkynylBisPyridine, 4). The second is a compound where the bipyridine is directly linked on the $3^{\prime}$-position of the central thiophene of the terthiophene chain, TBP (TerthiopheneBisPyridine, 6). The needed 4-bromo-2,2'-bipyridine was prepared by adapting literature protocols to obtain an optimized pathway (Figure S1 in SM) The protocol was performed on a $50 \mathrm{~g}$ scale of starting 2,2'-bipyridine.

The two monomer compounds were prepared by adapting literature methods to the synthetic strategy (Figure 2). The starting point was based on the identification of a common intermediate to be used for the synthesis of both compounds. The key intermediate is the $3^{\prime}$-bromo- $2: 2^{\prime}, 5^{\prime}: 2^{\prime \prime}$-terhiophene (1). Its preparation was derived from references $[37,38]$. The synthesis, based on a Suzuki reaction between the 2,3,5-tribromothiophene and the 2-thiopheneboronic acid, is straightforward but delicate, because a careful control of the ratio of reactants is necessary. The control of reaction temperature and time was needed to avoid fully substitution of the three bromine atoms. The maximum yield obtained was around $43 \%$, when the reaction was performed under MW heating at $130{ }^{\circ} \mathrm{C}$ for $30 \mathrm{~min}$.

The strategy to obtain compound 4 starts from 1, which was reacted with a Sonogashira protocol with the 2-methyl-3-butyn-2-ol, giving 2, which was deprotected by reaction with $\mathrm{KOH}$ in toluene:methanol, to give the alkyne 3 . This compound was finally used to obtain the final TABP (4) using again a Sonogashira reaction. TBP was prepared by reacting 1 with BuLi and trimethylborate, giving $5[39,40]$ which was not isolated and by a following Suzuki reaction with 4-bromo-2,2'-bipyridine to obtain the final compound 6 . The yield of 4 was about $6 \%$ over four steps, while for 6 was about $13 \%$. Since these two compounds were found to be able to form rhenium complexes, whose polymers gave very good carbon dioxide reduction performance [34] and due to the results of the present paper, we also worked on the optimization of the synthetic pathway and yield, obtaining substantial improvements [41,42]. 

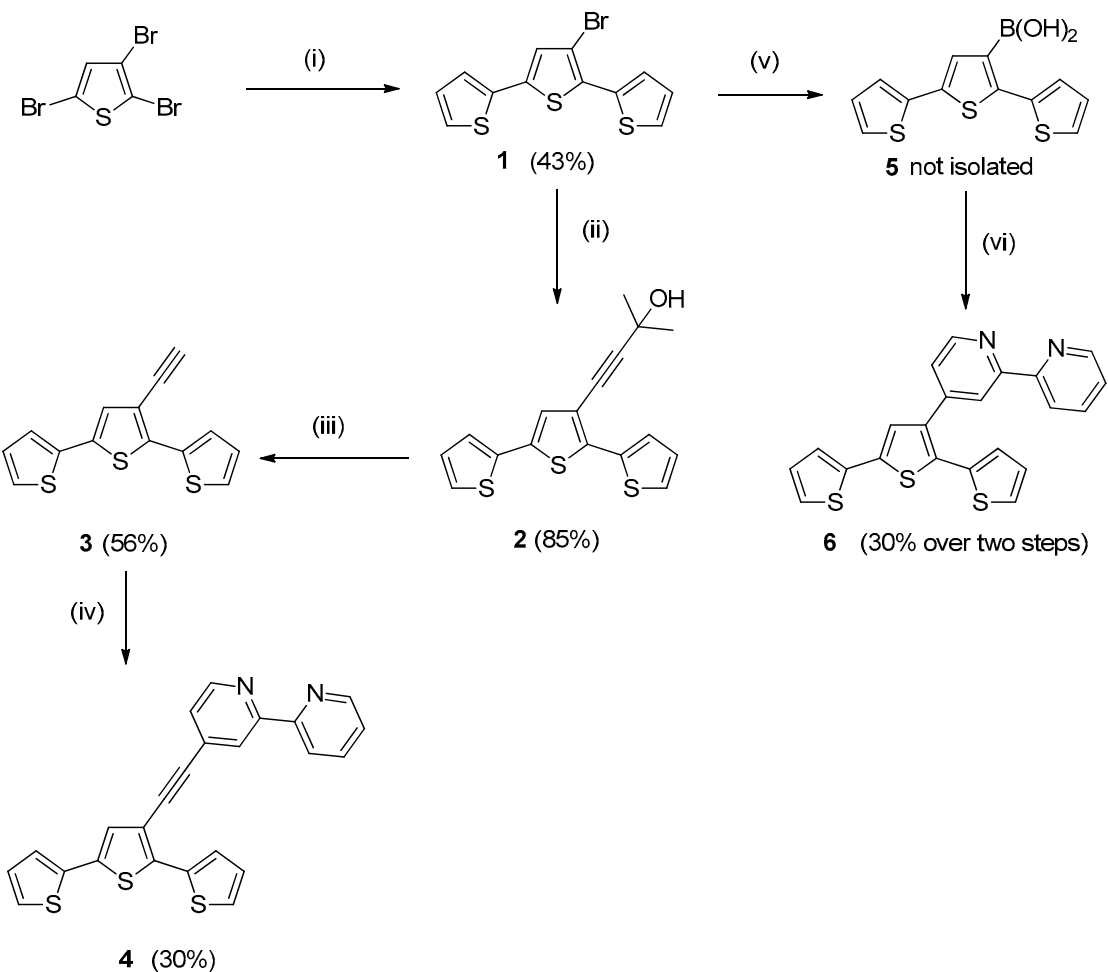

6 (30\% over two steps)

$4(30 \%)$

Figure 2. Synthetic pathway for terthiophene monomers $\operatorname{TABP}(4)$ and $\operatorname{TBP}(6)$ : (i) $\operatorname{Pd}\left(\mathrm{PPh}_{3}\right)_{4}$, DME, $1.5 \mathrm{M} \mathrm{Na}_{2} \mathrm{CO}_{3}, \mathrm{MW}$ (Microwaves), $130{ }^{\circ} \mathrm{C}$, 24h; (ii) 2-methyl-3-butyn-2-ol, $\mathrm{Pd}\left(\mathrm{PPh}_{3}\right)_{4}$, CuI, diisopropylamine (DIPA), Argon, reflux, 20 h; (iii) $\mathrm{KOH}$, Toluene:MeOH 1:1, reflux; (iv) 4-bromo-2,2'-bipyridine, $\mathrm{Pd}\left(\mathrm{PPh}_{3}\right)_{4}$, CuI, DIPA, Argon, reflux, $24 \mathrm{~h}$; (v) Lithium diisopropylamide (LDA), tetrahydrofuran (THF), trimethylborate, $-78^{\circ} \mathrm{C}, 1 \mathrm{~h}$, to rt $1 \mathrm{~h}$, rt $4 \mathrm{~h}$; (vi) 4-bromo-2,2'-bipyridine, $\left(\mathrm{PPh}_{3}\right)_{4}$, dimethoxyethane (DME), $1.5 \mathrm{M} \mathrm{Na}_{2} \mathrm{CO}_{3}, \mathrm{MW}, 120^{\circ} \mathrm{C}, 30 \mathrm{~min}$.

\subsection{Electrosynthesis}

Electrosyntheses of PT (polythiophene), PTABP, PTBP and their copolymers were performed using two strategies, both yielding homogeneous thin films. The first method consisted in cycling electrode potential (by Cyclic Voltammery, CV) in a range where monomer oxidation occurs, leading to the formation of polymers with high enough molecular mass to become insoluble in the electrolyte and deposit onto the working electrode surface. The current increased with every new cycle performed (Figure 3) demonstrating that the polymer deposited was not acting as a current blocking layer, but was conductive instead, allowing further growth of the polymeric film. With increasing scan number an increasing portion of the anodic current is due to polymer charging and oxidation, in addition to polymerization reaction, and this is the reason why we also observed the increase of the cathodic current with increasing scan number owing to polymer reduction and discharge. With increasing scan number we therefore observed the growth of the contribution of a capacitive current to an approximately constant faradaic component.

Instead of cycling the potential, in the second approach it was maintained at a constant value and the polymerization current was recorded (Figure S3 in SM). As we already observed for the first method, the polymer is conductive and its formation does not cause the current drop to zero at positive potential, even if a decrease with reaction time is observed. In both cases, the duration of the experiment can be modulated to deposit controlled amounts of polymers. We studied films obtained from the accumulation of charge in the range $2.5-25 \mathrm{mC}$, corresponding in the cases of PTABP and PTBP to $10-120 \mu \mathrm{g}$ deposited and, estimating the thin film bulk density as $0.8 \mathrm{~g} \mathrm{~cm}^{-3}$, average film thickness ranging from 30 to $330 \mathrm{~nm}$. It is more difficult to estimate the electrodeposited mass of the 
copolymers and the film thickness, since their composition is not known with accuracy and can only be estimated (see SM for details).

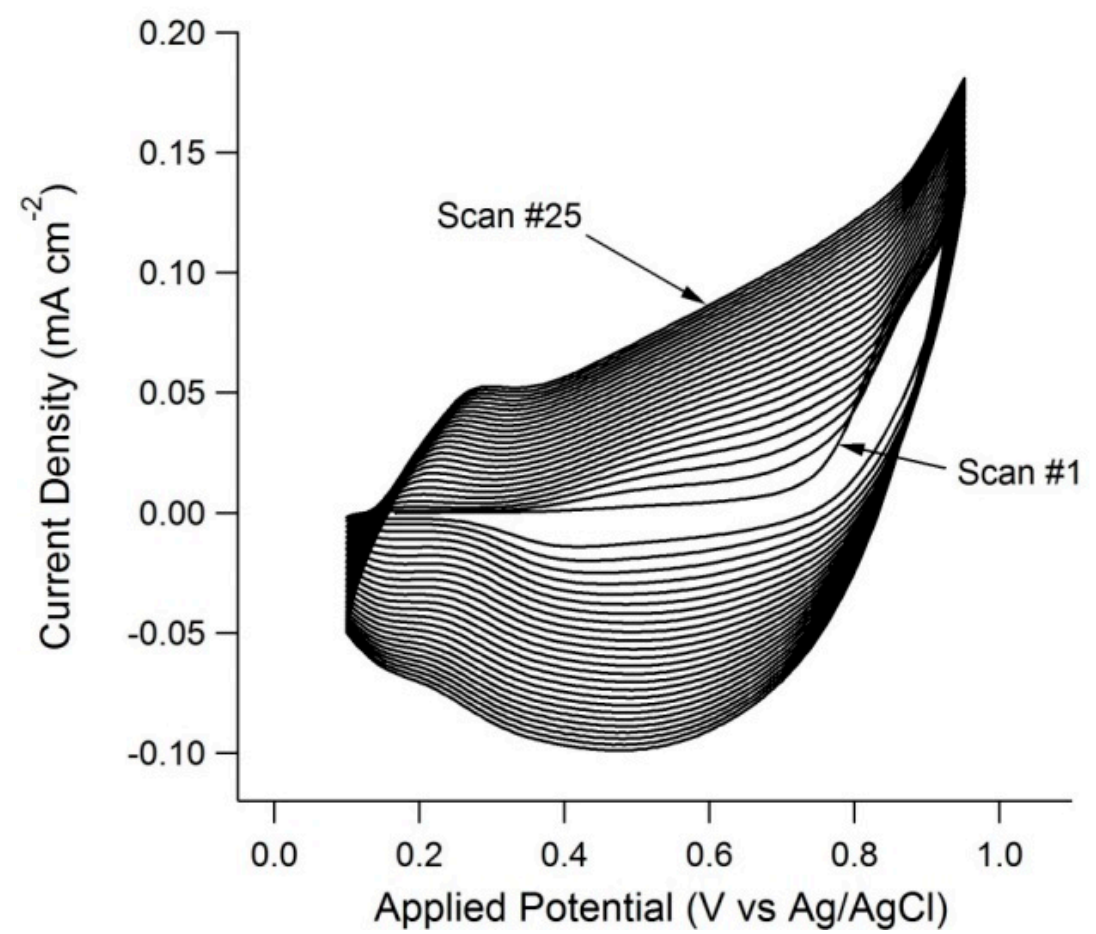

Figure 3. Electropolymerization of $2 \mathrm{mM}$ TABP in $0.1 \mathrm{M} \mathrm{TBAPF}_{6}$ in acetonitrile $/ \mathrm{CH}_{2} \mathrm{Cl}_{2}$ 1:1; transferred charge: $2.7 \mathrm{mC}$, PTABP mass deposited: $12 \mu \mathrm{g}$, estimated average film thickness: $38 \mathrm{~nm}$.

\subsection{Morphology}

Even though characterized by different roughness, all the thin films synthesized present similar morphological patterns, namely islands in relief with diameter ranging from $100 \mathrm{~nm}$ to $1000 \mathrm{~nm}$, where the electropolymerization process has been particularly effective (Figure 4 and Figures S4-S8 in SM). The elevation of the blocks, their shape and density differ in each sample. They are almost overlapping parallelepipeds in PT, while their shape becomes more irregular in PTBP, PTABP and P(TABP-co-T) and almost spherical in $\mathrm{P}(\mathrm{TBP}-\mathrm{co}-\mathrm{T})$. The polymers containing TABP are less rough and flatter, while PTBP and P(TBP-co-T) are rougher with the most prominent blocks. Thanks to this rough and porous morphology the films have significantly larger surface area compared to the geometric area of the conductive support. This can result in higher current density when an external bias is applied and in larger amounts of accumulated charge at the surface, i.e., improved capacitance, which can be further translated into increased charge carrier density upon irradiation, providing that their recombination kinetics is sufficiently slow.

\subsection{UV-Vis Spectroscopy}

The band-gap energy $E_{g}$ of the PTs synthesized was evaluated with Tauc theory. Equation (1) relates the optical absorption coefficient $\alpha$ and the photon energy h $v$ : [43]

$$
\alpha \mathrm{h} v=\mathrm{A}\left(\mathrm{h} v-\mathrm{E}_{\mathrm{g}}\right)^{\mathrm{n}}
$$

where $\mathrm{h}$ is the Planck constant, $v$ is the photon's frequency, A is a proportionality constant and $\mathrm{n}$ takes values from 0.5 to 3 , depending on the nature of the transition. In the case of a direct allowed transition $\mathrm{n}=0.5$. All the PTs synthesized are characterized by the presence of a direct band-gap, as witnessed by the linear behavior of the square of $\alpha h v$ as a function of the photon energy (Tauc plot of Figure 5, 
Table 1). Because of the large sub-band absorption, we employed the method proposed by Makula and coworkers [44] to obtain the band-gap, which is approximately 2.25-2.45 eV for PTABP, PTBP, while their copolymers with thiophene, $\mathrm{P}(\mathrm{TBAP}-\mathrm{co}-\mathrm{T})$ and $\mathrm{P}(\mathrm{TBP}-\mathrm{co}-\mathrm{T})$, and $\mathrm{PT}$ have lower band-gap, namely 1.9-2.05 eV. We found a second linear region for PTABP and PTBP, which can be extrapolated at around 1.5-1.6 eV, indicating the presence of localized states at those energy values. On the other hand in the copolymers this second region of linearity is less pronounced, as we found in the case of PT (Figure 5), even though sub-band absorption is not negligible.

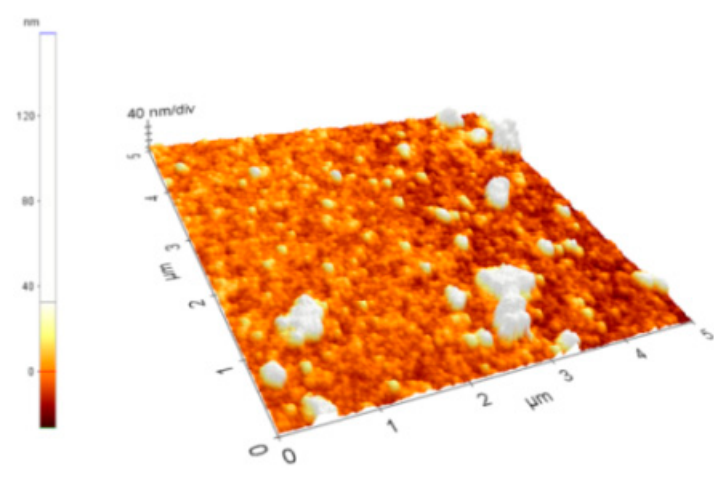

(a)

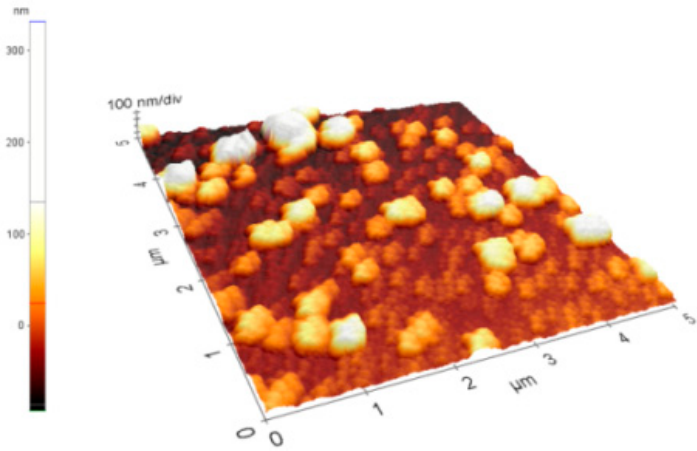

(c)

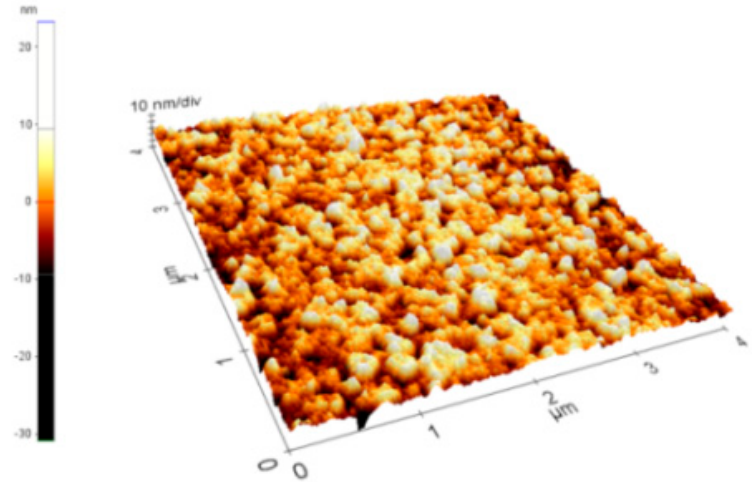

(b)

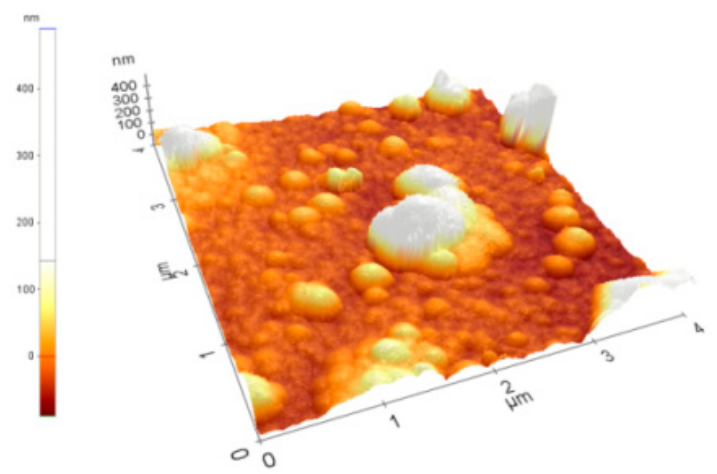

(d)

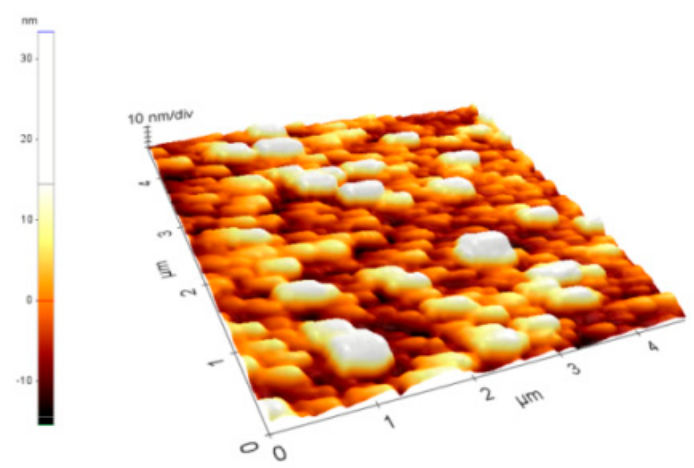

(e)

Figure 4. AFM topography of (a) PTABP, (b) P(TABP-co-T), (c) PTBP, (d) P(TBP-co-T) and (e) PT films electrosynthesized in potentiodynamic conditions. 


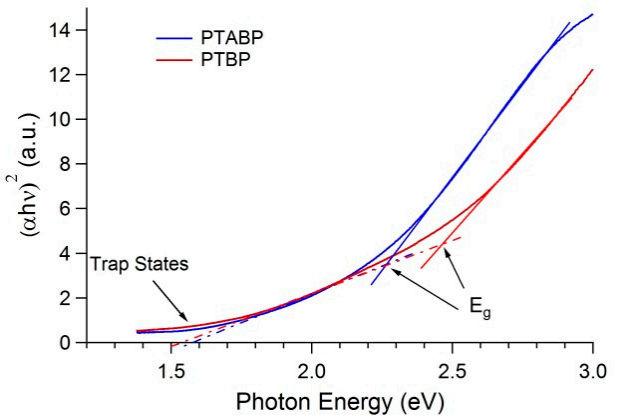

(a)

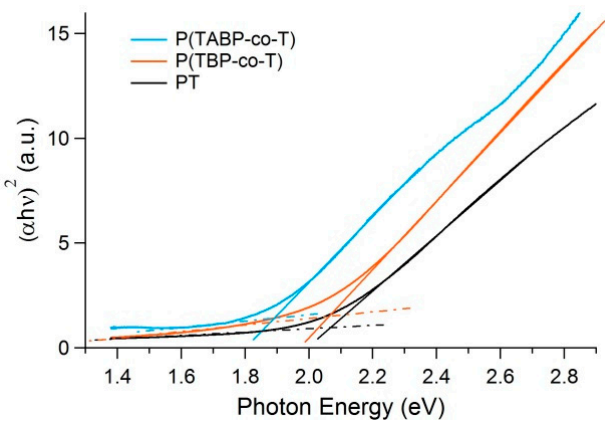

(b)

Figure 5. Evaluation of the electronic band-gap of the materials studied in the present work.

Table 1. Band-gap energy $E_{g}$ for the samples investigated in the present work.

\begin{tabular}{cc}
\hline Sample & $\left.\mathbf{E}_{\mathbf{g}} \mathbf{( e \mathbf { V }}, \pm \mathbf{0 . 0 5}\right)$ \\
\hline PTABP & 2.25 \\
PTBP & 2.45 \\
P(TABP-co-T) & 1.90 \\
P(TBP-co-T) & 2.05 \\
PT & 2.05 \\
\hline
\end{tabular}

\subsection{Electrochemistry}

In $\mathrm{CV}$ we observed a peak in the anodic scan at $0.4 \mathrm{~V}$ vs. $\mathrm{Ag} / \mathrm{AgCl}$ for PTABP, $0.5 \mathrm{~V}$ for $\mathrm{P}$ (TABP-CO-T) and $0.8 \mathrm{~V}$ for PTBP (Figures 6-8). The presence of this peak is not detectable in PT (Figure S9 in SM), nevertheless, also in this case, the current density increases with increasingly anodic potential, even though an anodic current peak is never reached, and above $1.2 \mathrm{~V} \mathrm{vs.} \mathrm{Ag} / \mathrm{AgCl}$ polymer degradation occurs, with the complete loss of the CV structure previously observed and of the photoactivity. We attributed its presence to high density of localized states at slightly higher energy than the VB, in agreement with the consistent sub-band absorption observed, while the further increase of the current recorded at more positive potential can be attributed to both valence band and shallower trap states and corresponds to polymer oxidation, which ultimately leads to its degradation. The stepwise oxidation of polythiophenes was already observed $[45,46]$. This behavior was explained in terms of the successive formation of polarons initially, then bipolarons and, eventually, oxidation to the metallic state (see Discussion section). We also detected two marked cathodic peaks at -0.6 and $-0.7 \mathrm{~V}$ vs. Ag/AgCl for PTBP (Figure 7) and a less evident peak at $-1.2 \mathrm{~V}$ vs. Ag/ AgCl for PTBAP. None of these features is observable in the case of P(TBAP-co-T) and PT.

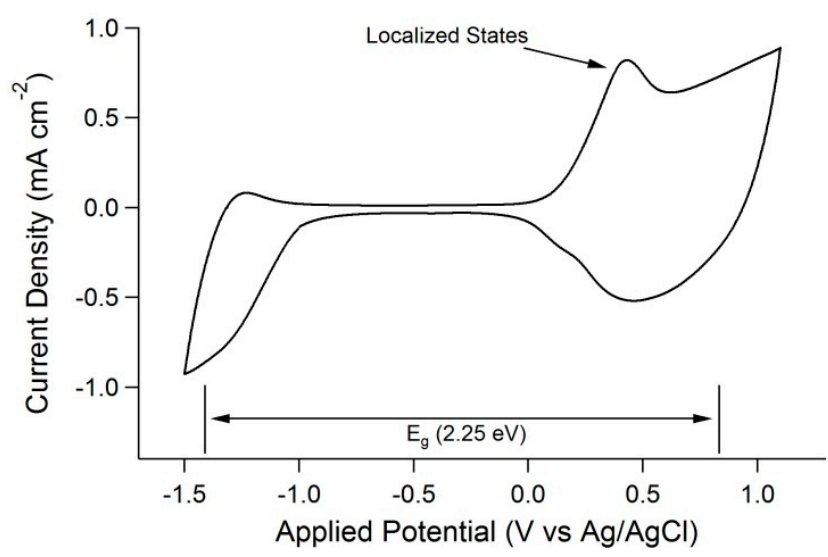

Figure 6. Cyclic voltammetry of electropolymerized PTABP at $0.5 \mathrm{~V} \mathrm{~s}^{-1}$ scan rate in $0.1 \mathrm{M} \mathrm{NaClO}_{4}$ in acetonitrile. The $\mathrm{E}_{\mathrm{g}}$ value measured with UV-Vis spectroscopy is reported together with the assignment proposed for the anodic peak at $0.4 \mathrm{~V}$ vs. $\mathrm{Ag} / \mathrm{AgCl}$. 


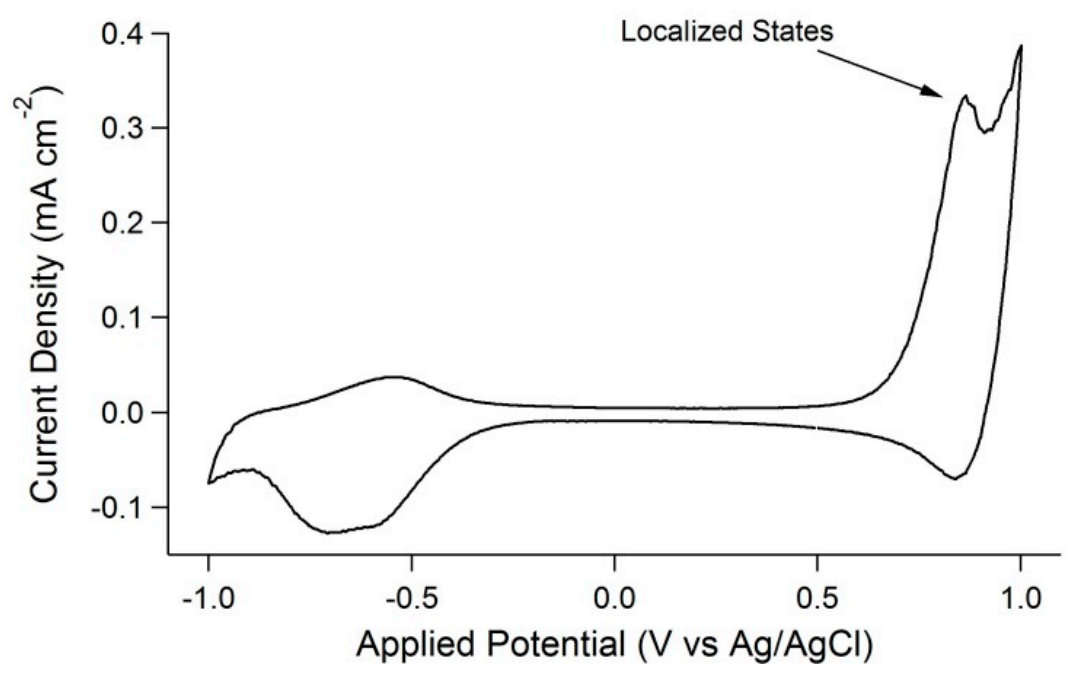

Figure 7. Cyclic voltammetry of electropolymerized TBP at $0.2 \mathrm{~V} \mathrm{~s}^{-1}$ scan rate in $0.1 \mathrm{M} \mathrm{NaClO}_{4}$ in acetonitrile. The $\mathrm{E}_{\mathrm{g}}$ value measured with $\mathrm{UV}$-Vis spectroscopy is reported together with the assignment proposed for the anodic peak at $0.8 \mathrm{~V}$ vs. $\mathrm{Ag} / \mathrm{AgCl}$.

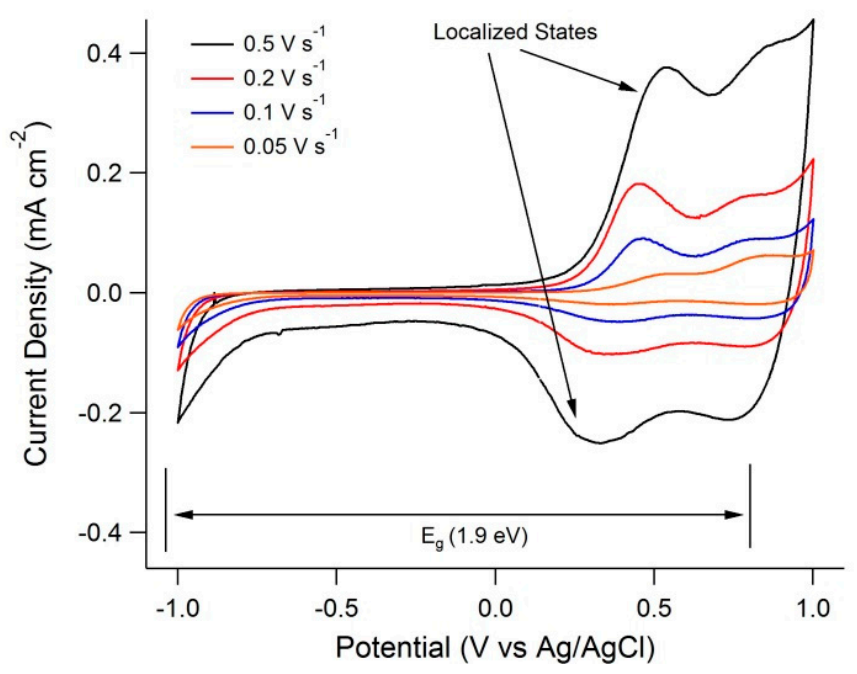

Figure 8. Cyclic voltammetry of electropolymerized $\mathrm{P}(\mathrm{TABP}-\mathrm{co}-\mathrm{T})$ at different scan rates in $0.1 \mathrm{M}$ $\mathrm{NaClO}_{4}$ in acetonitrile. The $\mathrm{E}_{\mathrm{g}}$ value measured with $\mathrm{UV}$-Vis spectroscopy is reported together with the assignment proposed for the anodic peak at $0.8 \mathrm{~V}$ vs. $\mathrm{Ag} / \mathrm{AgCl}$.

Further decreasing the potential polymer degradation occurs similarly to what was already observed in the anodic direction. The polymers containing TABP and TBP demonstrated marked photoactivity as witnessed by the sudden rise of the open circuit potential (OCP) under irradiation (Figure 9 and Figure S11 in SM). When irradiation is interrupted the OCP relaxes to the dark value over timescale of hundreds of seconds. The trend can be replicated many times. If the chronopotentiometry measurement is carried out immediately after the electrosynthesis, the OCP in the dark is located at more positive values and the onset of the photopotential is superimposed to this descending trend (Figure 10 and Figure S12 in SM), i.e., the photopotential (the difference between the OCP upon irradiation and in dark conditions) becomes larger with increasing time, and, therefore, with the stabilization of the dark OCP. The photoactivity of PTABP and PTBP and of the copolymers is further confirmed thanks to EIS and photocurrent measurements. In EIS we observed a reduction of the real and imaginary components of electrochemical impedance under irradiation (Figure S15 in SM). Photocurrents of PTABP and PTBP are in the order of 3-8 $\mu \mathrm{A} \mathrm{cm}-2$ depending on the applied potential, and more than $60 \%$ is retained after one hour of irradiation (Figure S16 in SM). These 
values are similar, even though slightly lower compared with previous reports on polythiophenes and inorganic semiconductors such as $\mathrm{ZnO}$ and $\mathrm{TiO}_{2}[24,28,47]$. Considering the porous morphology of PT electrodes, their capacitance will not behave ideally, and therefore the Mott-Schottky plots will deviate significantly from linearity, impeding the extraction of flat band potential and donor density with this strategy $[48,49]$.

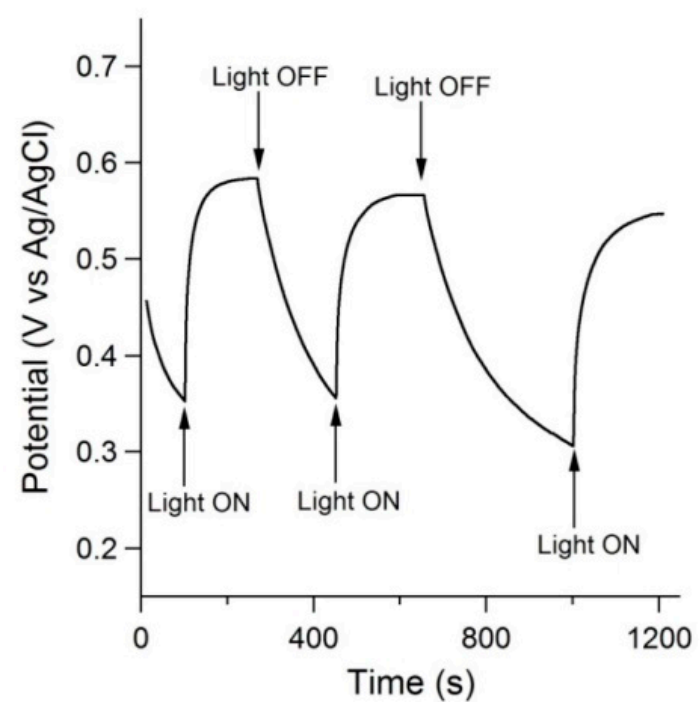

Figure 9. Chronopotentiometry of electropolymerized PTABP in $0.1 \mathrm{M} \mathrm{TBAPF}$ in acetonitrile/ $\mathrm{CH}_{2} \mathrm{Cl}_{2}$ 1:1.

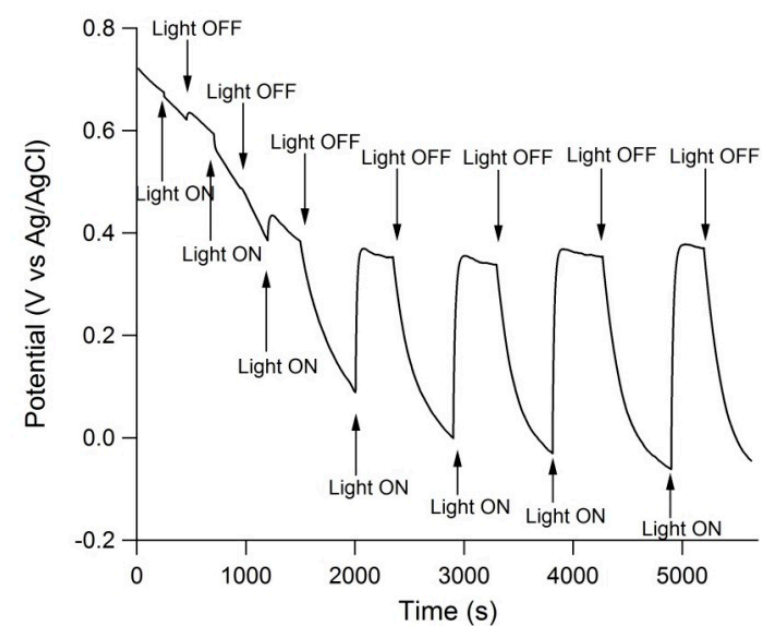

Figure 10. Chronopotentiometry of electropolymerized $\mathrm{P}(\mathrm{TABP}-\mathrm{co}-\mathrm{T})$ in $0.1 \mathrm{M} \mathrm{NaClO}_{4}$ in acetonitrile recorded immediately after electrosynthesis.

\section{Discussion}

Cyclic voltammetry is a tool to probe localized and extended states, conduction and valence band of semiconducting electrodes, indeed when the potential is swept toward positive values, the Fermi level in the semiconductor is displaced toward the valence band, while it is forced toward the conduction band when the potential in swept in the negative direction. When the applied potential forces the Fermi level inside the band-gap the current density recorded is in the order of $1 \mu \mathrm{A} \mathrm{cm}{ }^{-2}$ or less, because the resistivity of the material is high, while the density of states (DoS) is very low at those potential values. At energy levels close to the bands, the DoS usually increases exponentially because of the presence of localized states, and the increase becomes more pronounced when the applied potential crosses the conduction/valence band edges (Figure 11) [50]. Nonetheless, it is not easy to determine the position of the band edges by $\mathrm{CV}$, because the band pinning regime cannot be 
assured when trap states are populated, i.e., when the applied potential, and indeed the Fermi level, is about to reach the band edge, leading to uncertainty in the exact determination of the band edge energy. Conversely, the determination of localized state energy is more precise, especially in the case of deep traps. If there are no redox couples in solution the charge carriers promoted in semiconductor localized states due to the external bias are not transferred to solution, and, especially if the scan rate $\mathrm{s}$ is high, trap states can be reversibly populated and depopulated, leading to reversible voltammograms. In this case from the CV current it is possible to obtain the electrode chemical capacitance, which can be related to the DoS of the semiconductor, thanks to Equation (2):

$$
\mathrm{p}(\mathrm{E})=\frac{1}{\mathrm{eAd}} \frac{\mathrm{i}}{\mathrm{s}} \mathrm{dE}
$$

In which $\mathrm{p}$ is the density of monoelectronic states in the potential range $\mathrm{dE}$ per semiconductor unit volume, $\mathrm{A}$ is the geometric surface of the electrode, $\mathrm{d}$ its thickness, $\mathrm{i}$ is the CV current, $\mathrm{s}$ the scan rate.

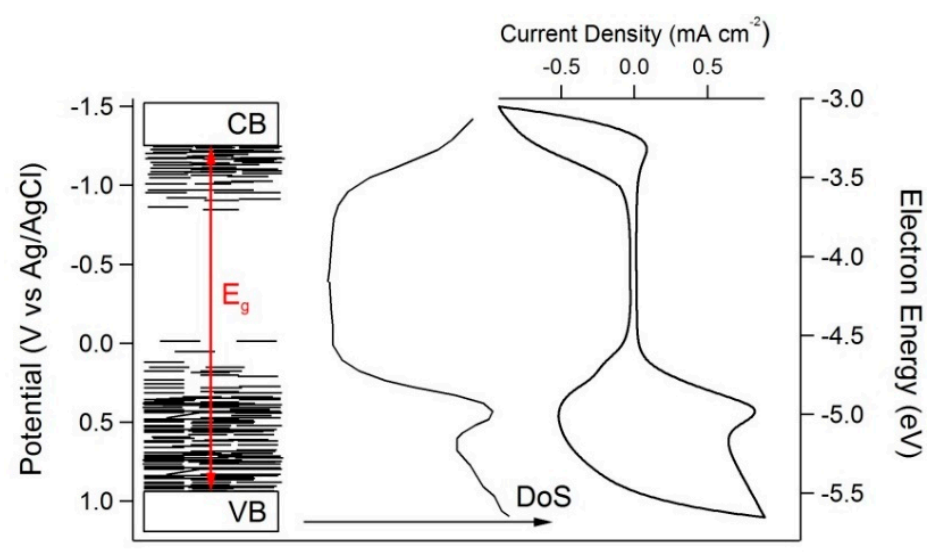

Figure 11. Schematic representation of the DoS (Density of States) and of the inferred representation of the extended and localized states in the case of PTABP as deducted from CV and UV-Vis spectrum.

\subsection{Band-Gap of PT Homo- and Copolymers}

Even though an accurate determination of the band-gap $E_{g}$ is cumbersome, we can compare the value measured with $\mathrm{UV}$-Vis spectroscopy and superimpose it to the $\mathrm{CV}$ of the corresponding material (Figures 6-8 and Figure S9 in SM). For the materials considered in the present work we can observe that the $\mathrm{E}_{\mathrm{g}}$ measured with UV-Vis spectroscopy is almost $1 \mathrm{eV}$ larger than the difference between the onset of anodic and that of cathodic current. Therefore we can assign the current from the onset for at least $300-400 \mathrm{mV}$ to localized states in proximity of valence and conduction bands. These localized states can be assigned to the creation of polarons and bipolarons, which are located inside the band-gap, up to $700 \mathrm{mV}$ from the VB edge [51]. The abundances found with UV-Vis are in very good agreement with this assignment, with even a second region of linearity at lower energy for PTABP and PTBP, which is not detected in the case of PT and copolymers (Figure 5), even though in the case of $\mathrm{P}(\mathrm{TABP}-\mathrm{co}-\mathrm{T})$ the spectrum slightly deviates from the sigmoidal shape exhibited by $\mathrm{P}(\mathrm{TBP}-\mathrm{co}-\mathrm{T})$ and PT, and its CV displays an anodic peak at $0.8 \mathrm{~V}$, which is absent in the case of PT (Figure S9 in SM). Localized states could also arise because of $2-3^{\prime}$ and $3-3^{\prime}$ binding between adjacent thiophene moieties, which can be present in all the homo- and copolymers synthesized.

\subsection{Chronopotentiometry Measurements}

OCP measurement is a powerful tool for the characterization of semiconducting electrodes, because it can reveal photoactivity, discriminate between n-type and p-type semiconductors and, eventually, quantify the photogenerated majority carrier density. The photoactivity is present in all the 
films synthesized, as witnessed by the difference between dark potential and its value upon irradiation, even though in the case of PT the effect is very limited (Table 2), probably because the undoping process for this polymer is significantly slower and the charge carrier density is already large, in the order of $10^{19} \mathrm{~cm}^{-3}$ (Figure S10b). Since in all cases the OCP equilibrates at more positive values compared to dark conditions, we can conclude that the samples considered in this work are p-type semiconductors. Indeed, in the case of p-type semiconductors under irradiation electrons are trapped and transferred to solution species faster than photoholes, which accumulate and shift the quasi Fermi level, and consequently the OCP, to more positive potential. On the other hand, irradiating n-type semiconductors leads to electron accumulation and to a negative shift of the OCP [52,53]. Steady state is achieved in approximately $100 \mathrm{~s}$, because charge carriers generation and their loss reach the same rate when a certain $\mathrm{p}_{\mathrm{ph}}$ is obtained. Since we excluded electron and hole scavengers from the electrolyte, charge carrier loss is mainly due to recombination. From a more quantitative point of view, PTBP has the most pronounced photopotential $(860 \mathrm{mV})$, while PTABP and P(TABP-co-T) are characterized by smaller values, $280 \mathrm{mv}$ and $430 \mathrm{mV}$, respectively. Larger photopotential values do not automatically correspond to larger photogenerated charge carrier density, because to convert the photopotential into photohole polaron density it is necessary to consider cyclic voltammetry [52]. As already mentioned earlier in the discussion, when CV is carried out at sufficiently high scan rate, and there are no redox species in solution, $\mathrm{p}(\mathrm{E})$ obtained can be used to convert the OCP recorded into photohole density in every instant, i.e., allowing the transformation of the $\mathrm{E} v \mathrm{vs}$. $\mathrm{t}$ plots into $\mathrm{p}_{\mathrm{ph}} \mathrm{vs.} \mathrm{t}$ plots, with Equation (3):

$$
\mathrm{p}_{\mathrm{ph}}=\frac{1}{\mathrm{eAd}} \int_{\mathrm{E}_{\text {dark }}}^{\mathrm{E}_{\text {light }}} \frac{\mathrm{i}}{\mathrm{s}} \mathrm{dE}
$$

In which $\mathrm{p}_{\mathrm{ph}}$ is the photogenerated hole polaron density. In this way we were able to obtain the charge carrier density corresponding to the potential obtained under steady state irradiation (Table 2), and we were also able to build the plot of $\mathrm{p}_{\mathrm{ph}}$ vs. time, as demonstrated in Figures S13 and S14 in SM. The $\mathrm{p}_{\mathrm{ph}}$ values obtained are in the order of $10^{19} \mathrm{~cm}^{-3}$, which is in the same order of magnitude of the photoelectron density recorded in the case of $\mathrm{TiO}_{2}$ [52]. The marked differences between samples observed in photopotential, ranging from $280 \mathrm{mV}$ to $860 \mathrm{mV}$, are levelled considering $\mathrm{p}_{\mathrm{ph}}$. All the samples investigated are characterized by densities of the same magnitude, in the range $1.1-1.4 \times 10^{19} \mathrm{~cm}^{-3}$, which is reasonable, considering the structural similarities. We can therefore assume that the photoactivity, which was observed also for PT containing other electron withdrawing substituents, such as the nitrostyryl group $[54,55]$ is not limited by the bipyridine moiety, while the triple bond of the TABP moiety does not seem to play a crucial role for the material photoactivity.

When irradiation is interrupted, the OCP decreases and tends to equilibrate to its dark value. This process is due to recombination, and we were able to obtain the recombination constant knowing $\mathrm{p}_{\mathrm{ph}}$ as a function of the time (Figures S13 and S14 in SM) during photopotential decay. We assumed that recombination is a first order process [52] and we obtained the recombination constant $\mathrm{k}_{\mathrm{r}}$ from Equation (3):

$$
\mathrm{k}_{\mathrm{r}}(\mathrm{E})=\frac{1}{\mathrm{p}_{\mathrm{ph}}} \frac{\mathrm{dp} \mathrm{p}_{\mathrm{ph}}}{\mathrm{dt}}
$$

Since photohole polaron reactivity depends on the energy of the localized state populated, with shallow traps being more oxidant and reactive than deep traps, $\mathrm{k}_{\mathrm{r}}$ is expected to depend on $\mathrm{E}$, and therefore also on $\mathrm{p}_{\mathrm{ph}}$. This dependence is more pronounced in the case of PTBP (Table 2), in which we observed a 6-fold increase of $\mathrm{k}_{\mathrm{r}}$ passing from $\mathrm{p}_{\mathrm{ph}}=5 \times 10^{18} \mathrm{~cm}^{-3}$ to $\mathrm{p}_{\mathrm{ph}}=1 \times 10^{19} \mathrm{~cm}^{-3}$, while in the case of PTABP and P(TABP-co-T) the increase was limited to approximately $15 \%$. Since the $\mathrm{p}_{\mathrm{ph}}$ recorded under steady state conditions is the result of a balance between charge carrier generation and their recombination, in agreement with this consideration we observed anticorrelation between $\mathrm{k}_{\mathrm{r}}$ values and $\mathrm{p}_{\mathrm{ph}}$ under steady state irradiation. When the OCP measurement is carried out immediately 
after the electropolymerization, as in Figure 10, we noted that in the first $2000 \mathrm{~s}$ of the measurement the OCP was even more positive than under steady state irradiation at the end of the experiment. Moreover OCP showed an almost exponential decay until it stabilized, in dark conditions, at approximately $-0.4 \mathrm{~V}$ vs. $\mathrm{Ag} / \mathrm{AgCl}$. Since this phenomenon was observable only if the experiment was carried out immediately after the electrosynthesis we attributed it to the fact that the polymer right after the synthesis is heavily doped, but the nature of this doping is uniquely electrochemical, and therefore very labile, as witnessed by the dark OCP decay in the first $2000 \mathrm{~s}$ of the experiment (Figure S12 in SM), which corresponds to an equivalent decay of charge carriers (Figure S13 in SM). This measurement gives also an estimate of the flat-band potential, which is located between 0.435 and $0.485 \mathrm{~V}$ vs. $\mathrm{Ag} / \mathrm{AgCl}$. Indeed at potentials more positive than the flat-band the photopotential is negative, because the semiconductor is in accumulation, whereas only when the OCP becomes more negative than the flat-band is the semiconductor in depletion, the most usual situation for a semiconductor-solution interface, and the photopotential is positive, as expected for p-type semiconductors.

Table 2. Photovoltage $\Delta \mathrm{V}_{\mathrm{ph}}$, photohole polaron density $\mathrm{p}_{\mathrm{ph}}$ and recombination constant $\mathrm{k}_{\mathrm{r}}$ evaluated at two different $\mathrm{p}_{\mathrm{ph}}$ for the samples investigated in the present work.

\begin{tabular}{|c|c|c|c|c|}
\hline Sample & $\Delta \mathrm{V}_{\mathrm{ph}}(\mathrm{V})$ & $p_{p h}\left(10^{19} \mathrm{~cm}^{-3}\right)$ & $k_{r}\left(10^{-3} s^{-1}\right)^{a}$ & $k_{r}\left(10^{-3} s^{-1}\right)^{b}$ \\
\hline PTABP & $0.28 \pm 0.02$ & $1.2 \pm 0.1$ & $15 \pm 1$ & $17.9 \pm 0.7$ \\
\hline PTBP & $0.86 \pm 0.03$ & $1.1 \pm 0.2$ & $18 \pm 2$ & $110 \pm 20$ \\
\hline P(TABP-co-T) & $0.43 \pm 0.01$ & $1.4 \pm 0.1$ & $7.0 \pm 0.8$ & $8.0 \pm 0.4$ \\
\hline
\end{tabular}

\section{Conclusions}

We demonstrated the synthesis of two bipyridine-functionalized terthiophenes that can be electropolymerized giving $\mathrm{p}$-type photoactive organic semiconductors, as witnessed by the OCP measurements in the dark and upon irradiation. The electrosynthesis is responsible for the oxidation of the polymers, resulting in high levels of doping; up-to $2 \times 10^{20} \mathrm{~cm}^{-3}$, where the material develops an accumulation layer and can be considered as a degenerate semiconductor. This high level of doping fades to less than $1 \times 10^{17} \mathrm{~cm}^{-3}$ in approximately one hour. We demonstrated that doping and undoping are reversible up to a certain level, beyond which over-oxidation occurs. The increase in OCP during steady state irradiation corresponds to the generation of charge carrier density in the range 1.1-1.4 $\times 10^{19} \mathrm{~cm}^{-3}$, depending on the material. Charge carrier density is in the same order of magnitude of the photoelectron density observed in the case of $\mathrm{TiO}_{2}$, and similar consideration holds for the pseudo-first order recombination constant of photogenerated charge carriers determined combining OCP measurement and CV. The resistance of the resultant organic semiconductor, as probed with EIS, is of the same order of magnitude of inorganic counterparts (e.g., $\mathrm{TiO}_{2}$ ) and is decreased upon irradiation, further confirming the photoactivity of the compounds and their suitability for implementation in a photoelectrochemical device.

Supplementary Materials: The following are available online at http:/ / www.mdpi.com/1996-1073/12/3/341/s1, synthetic details, supplementary AFM topographies and electrochemical results.

Author Contributions: The manuscript was written through contributions of all authors.

Funding: The financial support from project Ricerca Locale-Torino University-the project PHOTORECARB, Progetti di Ateneo/CSP 2012-Call 03-Università di Torino \& Compagnia di S. Paolo-is gratefully acknowledged.

Conflicts of Interest: The authors declare no conflict of interest. The funders had no role in the design of the study; in the collection, analyses, or interpretation of data; in the writing of the manuscript, or in the decision to publish the results. 


\section{References}

1. Armaroli, N.; Balzani, V. The future of energy supply: Challenges and opportunities. Angew. Chem.-Int. Edit. 2007, 46, 52-66. [CrossRef] [PubMed]

2. Lund, J.W.; Boyd, T.L. Direct utilization of geothermal energy 2015 worldwide review. Geothermics 2016, 60, 66-93. [CrossRef]

3. Solangi, K.H.; Islam, M.R.; Saidur, R.; Rahim, N.A.; Fayaz, H. A review on global solar energy policy. Renew. Sustain. Energy Rev. 2011, 15, 2149-2163. [CrossRef]

4. Jean, J.; Brown, P.R.; Jaffe, R.L.; Buonassisi, T.; Bulovic, V. Pathways for solar photovoltaics. Energy Environ. Sci. 2015, 8, 1200-1219. [CrossRef]

5. Global Wind Energy Council. Global Wind Report-Annual Market Update. 2011. Available online: https: / / windeurope.org/about-wind/statistics/global/global-wind-report-2011/ (accessed on 21 January 2019).

6. Iwase, A.; Ng, Y.H.; Ishiguro, Y.; Kudo, A.; Amal, R. Reduced Graphene Oxide as a Solid-State Electron Mediator in Z-Scheme Photocatalytic Water Splitting under Visible Light. J. Am. Chem. Soc. 2011, 133, 11054-11057. [CrossRef] [PubMed]

7. Li, P.; Zhou, Y.; Li, H.; Xu, Q.; Meng, X.; Wang, X.; Xiao, M.; Zou, Z. All-solid-state Z-scheme system arrays of $\mathrm{Fe}_{2} \mathrm{~V}_{4} \mathrm{O}_{13} / \mathrm{RGO} / \mathrm{CdS}$ for visible light-driving photocatalytic $\mathrm{CO}_{2}$ reduction into renewable hydrocarbon fuel. Chem. Commun. 2015, 51, 800-803. [CrossRef] [PubMed]

8. Zhou, P.; Yu, J.; Jaroniec, M. All-Solid-State Z-Scheme Photocatalytic Systems. Adv. Mater. 2014, 26, $4920-4935$. [CrossRef] [PubMed]

9. Maeda, K.; Lu, D.; Domen, K. Solar-Driven Z-scheme Water Splitting Using Modified $\mathrm{BaZrO}_{3}-\mathrm{BaTaO}_{2} \mathrm{~N}$ Solid Solutions as Photocatalysts. ACS Catal. 2013, 3, 1026-1033. [CrossRef]

10. Maeda, K. Z-Scheme Water Splitting Using Two Different Semiconductor Photocatalysts. ACS Catal. 2013, 3, 1486-1503. [CrossRef]

11. Balzani, V.; Credi, A.; Venturi, M. Photochemical Conversion of Solar Energy. ChemSusChem 2008, 1, $26-58$. [CrossRef]

12. Benniston, A.C.; Harriman, A. Artificial photosynthesis. Mater. Today 2008, 11, 26-34. [CrossRef]

13. Carroll, G.M.; Gamelin, D.R. Kinetic Analysis of Photoelectrochemical Water Oxidation by Mesostructured Co-Pi $/ \alpha-\mathrm{Fe}_{2} \mathrm{O}_{3}$ Photoanodes. J. Mater. Chem. A 2016, 4, 2986-2994. [CrossRef]

14. Young, E.R.; Costi, R.; Paydavosi, S.; Nocera, D.G.; Bulovic, V. Photo-Assisted Water Oxidation with Cobalt-Based Catalyst Formed from Thin-Film Cobalt Metal on Silicon Photoanodes. Energy Environ. Sci. 2011, 4, 2058-2061. [CrossRef]

15. Pilli, S.K.; Furtak, T.E.; Brown, L.D.; Deutsch, T.G.; Turner, J.A.; Herring, A.M. Cobalt-Phosphate (Co-Pi) Catalyst Modified Mo-Doped $\mathrm{BiVO}_{4}$ Photoelectrodes for Solar Water Oxidation. Energy Environ. Sci. 2011, 4 , 5028-5034. [CrossRef]

16. McDonald, K.J.; Choi, K.-S. Photodeposition of Co-Based Oxygen Evolution Catalysts on $\alpha-\mathrm{Fe}_{2} \mathrm{O}_{3}$ Photoanodes. Chem. Mater. 2011, 23, 1686-1693. [CrossRef]

17. Windle, C.D.; Perutz, R.N. Advances in molecular photocatalytic and electrocatalytic $\mathrm{CO}_{2}$ reduction. Coord. Chem. Rev. 2012, 256, 2562-2570. [CrossRef]

18. Franco, F.; Cometto, C.; Garino, C.; Minero, C.; Sordello, F.; Nervi, C.; Gobetto, R. Photo- and Electrocatalytic Reduction of $\mathrm{CO}_{2}$ by $\left[\operatorname{Re}(\mathrm{CO})_{3}\left\{\alpha, \alpha^{\prime}\right.\right.$-Diimine-(4-piperidinyl-1,8-naphthalimide) $\left.\} \mathrm{Cl}\right]$ Complexes. Eur. J. Inorg. Chem. 2015, 2015, 296-304. [CrossRef]

19. Franco, F.; Cometto, C.; Ferrero Vallana, F.; Sordello, F.; Priola, E.; Minero, C.; Nervi, C.; Gobetto, R. A local proton source in a $[\mathrm{Mn}(\mathrm{bpy}-\mathrm{R})(\mathrm{CO}) \mathrm{Br}]$-type redox catalyst enables $\mathrm{CO}$ reduction even in the absence of Bronsted acids. Chem. Commun. (Cambridge, UK) 2014, 50, 14670-14673. [CrossRef]

20. Costentin, C.; Robert, M.; Savéant, J.-M. Current Issues in Molecular Catalysis Illustrated by Iron Porphyrins as Catalysts of the $\mathrm{CO}_{2}$-to-CO Electrochemical Conversion. Acc. Chem. Res. 2015, 48, 2996-3006. [CrossRef]

21. Yuan, Y.-J.; Yu, Z.-T.; Zhang, J.-Y.; Zou, Z.-G. A copper(i) dye-sensitised $\mathrm{TiO}_{2}$-based system for efficient light harvesting and photoconversion of $\mathrm{CO}_{2}$ into hydrocarbon fuel. Dalton Trans. 2012, 41, 9594-9597. [CrossRef]

22. Roncali, J. Conjugated poly(thiophenes): Synthesis, functionalization, and applications. Chem. Rev. 1992, 92, 711-738. [CrossRef] 
23. Sun, H.; Hu, Z.; Zhong, C.; Zhang, S.; Sun, Z. Quantitative Estimation of Exciton Binding Energy of Polythiophene-Derived Polymers Using Polarizable Continuum Model Tuned Range-Separated Density Functional. J. Phys. Chem. C 2016, 120, 8048-8055. [CrossRef]

24. Suppes, G.; Ballard, E.; Holdcroft, S. Aqueous photocathode activity of regioregular poly(3-hexylthiophene). Polym. Chem. 2013, 4, 5345-5350. [CrossRef]

25. Kormányos, A.; Hursán, D.; Janáky, C. Photoelectrochemical Behavior of PEDOT/Nanocarbon Electrodes: Fundamentals and Structure-Property Relationships. J. Phys. Chem. C 2018, 122, 13682-13690. [CrossRef]

26. Steier, L.; Holliday, S. A bright outlook on organic photoelectrochemical cells for water splitting. J. Mater. Chem. A 2018, 6, 21809-21826. [CrossRef]

27. Kalaji, M.; Nyholm, L.; Peter, L.M.; Rudge, A.J. Photoelectrochemical properties of polyaniline films. J. Electroanal. Chem. Interfacial Electrochem. 1991, 310, 113-126. [CrossRef]

28. Hursán, D.; Kormányos, A.; Rajeshwar, K.; Janáky, C. Polyaniline films photoelectrochemically reduce $\mathrm{CO}_{2}$ to alcohols. Chem. Commun. 2016, 52, 8858-8861. [CrossRef] [PubMed]

29. Nattestad, A.; Perera, I.; Spiccia, L. Developments in and prospects for photocathodic and tandem dye-sensitized solar cells. J. Photochem. Photobiol. C: Photochem. Rev. 2016, 28, 44-71. [CrossRef]

30. Koppenol, W.H.; Rush, J.D. Reduction potential of the carbon dioxide/carbon dioxide radical anion: A comparison with other C1 radicals. J. Phys. Chem. 1987, 91, 4429-4430. [CrossRef]

31. Johansson, T.; Mammo, W.; Svensson, M.; Andersson, M.R.; Inganäs, O. Electrochemical bandgaps of substituted polythiophenes. J. Mater. Chem. 2003, 13, 1316-1323. [CrossRef]

32. Takahashi, Y.; Taura, S.; Akiyama, T.; Yamada, S. Electropolymerized Polythiophene Photoelectrodes with Density-Controlled Gold Nanoparticles. Langmuir 2012, 28, 9155-9160. [CrossRef] [PubMed]

33. Alves-Santos, M.; Jorge, L.M.M.; Caldas, M.J.; Varsano, D. Electronic Structure of Interfaces between Thiophene and $\mathrm{TiO}_{2}$ Nanostructures. J. Phys. Chem. C 2014, 118, 13539-13544. [CrossRef]

34. Sun, C.; Prosperini, S.; Quagliotto, P.; Viscardi, G.; Yoon, S.S.; Gobetto, R.; Nervi, C. Electrocatalytic Reduction of $\mathrm{CO}_{2}$ by Thiophene-substituted Rhenium(I) Complexes and by their Polymerized Films. Dalton Trans. 2016, 45, 14678-14688. [CrossRef]

35. Egbe, D.A.M.; Amer, A.M.; Klemm, E. Improved synthesis of 4-bromo-2,2'-bipyridine: A start material for low-molecular-weight model compounds. Des. Monomers Polym. 2001, 4, 169-175. [CrossRef]

36. Demnitz, F.W.J.; D'Heni, M.B. A HIGH YIELDING PREPARATION OF 2,2'-BIPYRIDINE-1-OXIDE. Org. Prep. Proced. Int. 1998, 30, 467-469. [CrossRef]

37. Manca, P.; Pilo, M.I.; Casu, G.; Gladiali, S.; Sanna, G.; Scanu, R.; Spano, N.; Zucca, A.; Zanardi, C.; Bagnis, D.; et al. A new terpyridine tethered polythiophene: Electrosynthesis and characterization. J. Polym. Sci. Part A Polym. Chem. 2011, 49, 3513-3523. [CrossRef]

38. Lee, T.-Y.; Shim, Y.-B.; Shin, S.C. Simple preparation of terthiophene-3'-carboxylic acid and characterization of its polymer. Synth. Met. 2002, 126, 105-110. [CrossRef]

39. de Bettencourt-Dias, A.; Viswanathan, S.; Rollett, A. Thiophene-Derivatized Pybox and Its Highly Luminescent Lanthanide Ion Complexes. J. Am. Chem. Soc. 2007, 129, 15436-15437. [CrossRef]

40. Collis, G.E.; Burrell, A.K.; Scott, S.M.; Officer, D.L. Toward Functionalized Conducting Polymers: Synthesis and Characterization of Novel $\beta$-(Styryl)terthiophenes. J. Org. Chem. 2003, 68, 8974-8983. [CrossRef]

41. Quagliotto, P.; Barbero, N.; Barolo, C.; Buscaino, R.; Carfora, P.; Prosperini, S.; Viscardi, G. Water based surfactant-assisted synthesis of thienylpyridines and thienylbipyridine intermediates. Dyes Pigm. 2017, 137, 468-479. [CrossRef]

42. Quagliotto, P.; Prosperini, S.; Viscardi, G. Improved Synthesis of a Terthiophene-Based Monomeric Ligand That Forms a Highly Active Polymer for the Carbon Dioxide Reduction. Lett. Org. Chem. 2017, 14, 472-478. [CrossRef]

43. Tauc, J. Optical properties of amorphous semiconductors. In Amorphous and Liquid Semiconductor; Tauc, J., Ed.; Plenum Publ. Co: New York, NY, USA, 1974; pp. 159-220.

44. Makuła, P.; Pacia, M.; Macyk, W. How To Correctly Determine the Band Gap Energy of Modified Semiconductor Photocatalysts Based on UV-Vis Spectra. J. Phys. Chem. Lett. 2018, 9, 6814-6817. [CrossRef]

45. Suarez-Herrera, M.F.; Feliu, J.M. Electrochemical Properties of Thin Films of Polythiophene Polymerized on Basal Plane Platinum Electrodes in Nonaqueous Media. J. Phys. Chem. B 2009, 113, 1899-1905. [CrossRef] [PubMed] 
46. Chen, X.; Inganäs, O. Three-Step Redox in Polythiophenes: Evidence from Electrochemistry at an Ultramicroelectrode. J. Phys. Chem. 1996, 100, 15202-15206. [CrossRef]

47. Sordello, F.; Berruti, I.; Gionco, C.; Paganini, M.C.; Calza, P.; Minero, C. Photocatalytic performances of rare earth element-doped zinc oxide toward pollutant abatement in water and wastewater. Appl. Catal. B Environ. 2019, 245, 159-166. [CrossRef]

48. Ernè, B.H.; Vanmaekelbergh, D.; Kelly, J.J. Morphology and strongly enhanced photoresponse of GaP electrodes made porous by anodic etching. J. Electrochem. Soc. 1996, 143, 305-314. [CrossRef]

49. Konstantinov, A.O.; Harris, C.I.; Janzen, E. Electrical properties and formation mechanism of porous silicon carbide. Appl. Phys. Lett. 1994, 65, 2699-2701. [CrossRef]

50. Fabregat-Santiago, F.; Mora-Sero, I.; Garcia-Belmonte, G.; Bisquert, J. Cyclic voltammetry studies of nanoporous semiconductors. Capacitive and reactive properties of nanocrystalline $\mathrm{TiO}_{2}$ electrodes in aqueous electrolyte. J. Phys. Chem. B 2003, 107, 758-768. [CrossRef]

51. Bredas, J.L.; Street, G.B. Polarons, bipolarons, and solitons in conducting polymers. Acc. Chem. Res. 1985, 18, 309-315. [CrossRef]

52. Monllor-Satoca, D.; Gómez, R. Electrochemical Method for Studying the Kinetics of Electron Recombination and Transfer Reactions in Heterogeneous Photocatalysis: The Effect of Fluorination on $\mathrm{TiO}_{2} \mathrm{Nanoporous}$ Layers. J. Phys. Chem. C 2007, 112, 139-147. [CrossRef]

53. Sordello, F.; Maurino, V.; Minero, C. Photoelectrochemical study of $\mathrm{TiO}_{2}$ inverse opals. J. Mater. Chem. 2011, 21, 19144-19152. [CrossRef]

54. Cutler, C.A.; Burrell, A.K.; Collis, G.E.; Dastoor, P.C.; Officer, D.L.; Too, C.O.; Wallace, G.G. Photoelectrochemical cells based on polymers and copolymers from terthiophene and nitrostyrylterthiophene. Synth. Met. 2001, 123, 225-237. [CrossRef]

55. Cutler, C.A.; Burrell, A.K.; Officer, D.L.; Too, C.O.; Wallace, G.G. Effect of electron withdrawing or donating substituents on the photovoltaic performance of polythiophenes. Synth. Met. 2002, 128, 35-42. [CrossRef]

(C) 2019 by the authors. Licensee MDPI, Basel, Switzerland. This article is an open access article distributed under the terms and conditions of the Creative Commons Attribution (CC BY) license (http:/ / creativecommons.org/licenses/by/4.0/). 